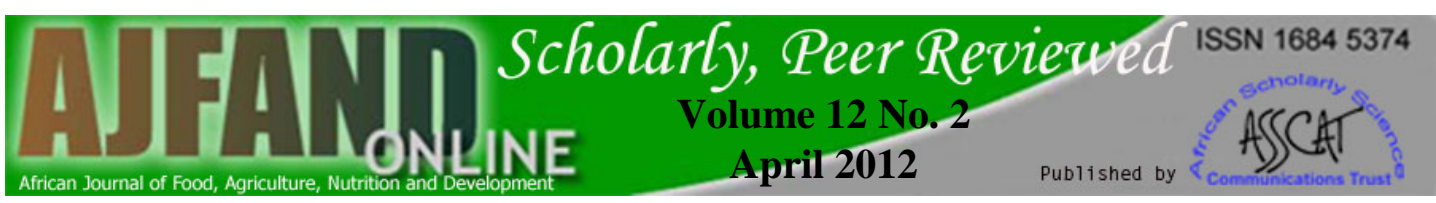

\title{
NUTRITIONAL STATUS OF CHILDREN IN FOOD INSECURE HOUSEHOLDS IN TWO DISTRICTS OF NORTH SHOWA ZONE, ETHIOPIA
}

\author{
Aweke KA*1, Habtamu F ${ }^{1}$ and G Akalu ${ }^{2}$
}

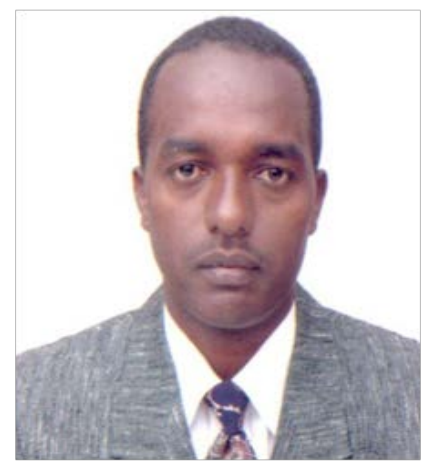

Aweke Kebede Arfassa

*Corresponding Author e-mail: awekekeb@gmail.com

${ }^{1}$ Ethiopian Health and Nutrition Research Institute (EHNRI), Addis Ababa, Ethiopia, P. O .Box: 1242, Addis Ababa, Ethiopia.

${ }^{2}$ Action Against Hunger, ACF-USA, Republic of South Sudan. 


\section{ABSTRACT}

Malnutrition is one of the leading causes of morbidity and mortality of children in Ethiopia. However, little information is available on nutritional status of the lower socioeconomic segment of the community to devise targeted tackling solutions and overcome severe malnutrition. Therefore, the objective of this study is to assess nutritional status of children and other related information in food insecure households. Two hundred food insecure households (HHs) were selected from two districts of North Showa zone of Amhara in 2007. The criteria for inclusion were being landless, oxen-less, and/ or female headed. Anthropometric and clinical data were collected from a total of 239 (151<5yrs and 88, 6-12yrs) children. Data on demographic, childcare, feeding practices and morbidity status of children were collected using an interview, community focus group discussion and secondary data from district offices. The overall prevalence of stunting, underweight and wasting was $54.2 \%, 40.2 \%$ and $10.6 \%$, respectively. Prevalence of night blindness and Bitot's spot were $3.1 \%$ and $3.5 \%$, respectively. The median level of urinary iodine excretion by $6-$ 12 years children was $1.5 \mu \mathrm{g} / \mathrm{L}$. Seventeen percent of the children were found iron deficient. Exclusive breastfeeding up to 6 month was practiced by less than $20 \%$ of the households. About fifty six percent of the households have cropland less than half a hectare and $50.8 \%$ of the households are getting water from unprotected well or spring. The main type of toilet facility being used was open bush/field (84.5\%). The main income of the households was agriculture. The majority (45-50\%) of the household heads in both districts are in the age ranges of 20-30 years. Fifty percent of the household heads can read and write. Lack of enough arable land, unreliable rain fall, extension of desertification, lack of scientific agricultural knowledge, absence of irrigation schemes, and shortage of skill in land use and management are some of the problems reported to contribute to food insecurity. The households are under severe malnutrition, food insecurity and poor childcare. Therefore, improvement of household resources by initiation of income generating livelihood options and knowledge based agriculture is needed.

Key words: malnutrition, food insecurity, North Showa 


\section{INTRODUCTION}

Child malnutrition continues to be a major public health problem in Ethiopia [1, 2]. The United Nations Human Development Index shows that Ethiopia is one of the least developed countries in the world with78\% of the population estimated to be living on less than US\$ 2 a day [3]. Malnutrition impedes body's metabolism and retards utilization of immunity. Malnourished children are more likely to develop severe infections because of deficiencies in immunocompetence [4]. Children are most vulnerable to malnutrition due to low dietary intake, inaccessibility to food, inequitable distribution of food within the household, improper food storage and preparation, dietary taboos and infectious diseases [5, 6]. Especially, micronutrient deficiencies are a result of inadequate intake or inefficient utilization of available micronutrients due to infections and parasitic infestations [1]. This paper presents results of a study on the nutritional status of children in food insecure households.

\section{MATERIALS AND METHODS}

A cross-sectional survey with descriptive and analytical components was carried out in two districts of North Showa zone to estimate malnutrition rate of children in food insecure households. The subjects were selected based on socioeconomic factors and gender, which might contribute to food insecurity status of the HHs. The inclusion criteria for HHs were: being land and oxen less, or female headed household and productive safety net beneficiary. The targeted study subjects were children under five years old. Since stable iodine concentration is observed in school age children as recommended by WHO (8), this group is assessed to determine level of iodine deficiency disorder. Based on the above criteria set, a hundred food in-secure households were selected and assessed in each district. Therefore, the survey was conducted on 200 households already identified as the poorest of the poor by community leaders and local administrative unit based on the aforementioned criteria. Hence, the sampling coverage is $100 \%$. For the study, all children between the ages of 6 and59 months belonging to the selected households are included in the study.

Anthropometric (length/height, weight, age, MUAC and sex) and clinical data were collected from a total of 151 children under five years and 88 children of 6-12 years from the $200 \mathrm{HHs}$ following WHO [7] guideline for nutrition assessment. Data on socio-demographic, water and sanitation, child and maternal care, feeding practices, growth monitoring, immunization and morbidity status of children were collected from these households using a structured and pre-tested questionnaire.

The hemoglobin concentration of each subject was measured in a finger-prick blood sample using a Hemocue (haemoglobinometer, Angelholm, Sweden). Clinical Vitamin A Deficiency (VAD), Iron Deficiency Anemia (IDA), Iodine Deficiency Disorder (IDD) and clinical manifestation of malnutrition were investigated by a trained nurse. In addition, urine was collected from 6-12 years old children for determination of urinary iodine level using wet digestion; modified method of Sandell-Kolthoff [8]. Goiter was assessed by palpation following the guideline of WHO (8). The nutritional status of the study children was computed using nutritional indices: weight-for-age, weight-for-height, and height-for-age, according to the

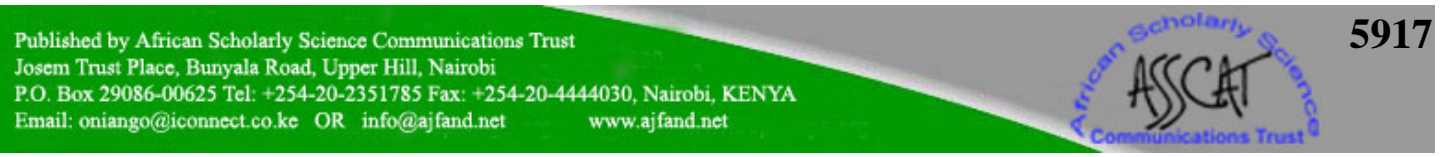


NCHS reference standard taking -2.S.D as the cut-off point (under-weight, wasting, and stunting). The EPI-INFO version 3.4.3 and SPSS 12.0 for windows were used to enter and analyze data.

Verbal informed consent was obtained after the purpose and methods of the study had been fully explained to mothers or caregivers of each child. Clinical cases observed during the survey were advised and referred to nearest health institution for treatment. The study was conducted according to rules and regulation of Research and Ethical Clearance committee (RECC) of Ethiopian Health and Nutrition Research Institute (EHNRI).

\section{RESULTS}

\section{Demographic}

The overall percentages of male- and female- headed households studied were $41 \%$ and 59\%, respectively (Table 1). The national estimate for female-headed households is $20 \%$ [1] in rural community. The main source of income of the households was agriculture. The size of household members ranged from one to nine persons with a mean size of 4 . The proportion of households having household size of 4-6 persons was relatively higher (60\%) in Lalomama than Gerakeya district. The majority of the household heads were young with the age of 20-30 years (45\%) and little formal education (50\%).

\section{Nutritional status}

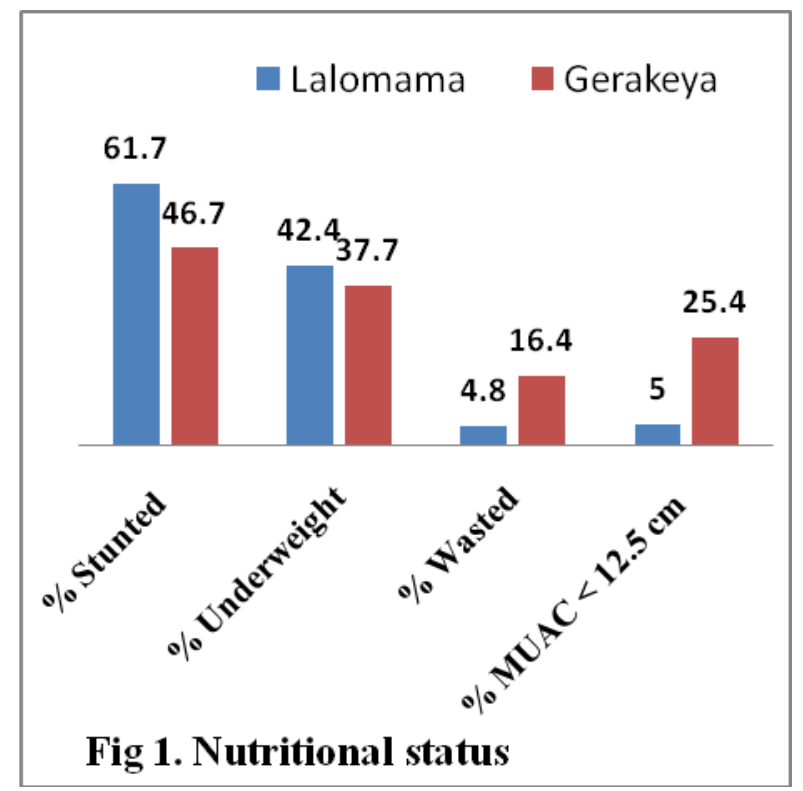

\section{Anthropometry}

Malnutrition levels were high in both districts as shown in Fig. 1. The overall prevalence of stunting, underweight and wasting was 54.2\%, 40.2\% and $10.6 \%$, respectively. A higher rate of stunting which is a direct reflection of chronic poverty is found in Lalomama (61.7\%). A high prevalence of wasting (16.4\%) and very low 


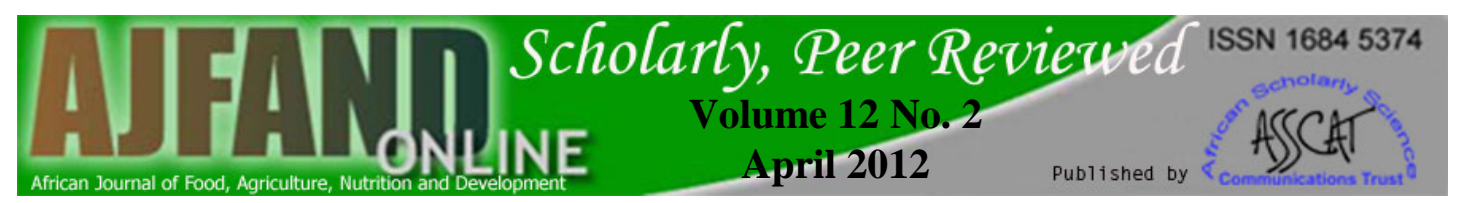

Middle Upper-Arm Circumference (MUAC $<12.5 \mathrm{~cm}$ ) was observed in Gerakeya district.

\section{Micronutrients deficiency}

The prevalence of Xerophthalmia as detected by clinical symptoms and signs is shown in Table 2. Bitot's spot and night blindness were found to be $3.5 \%$ and $3.1 \%$ in Lalomama and $3.6 \%$ and nil in Gerakeya, respectively. The prevalence of anemia in children was found to be $8.6 \%$ and $25.4 \%$ in Lalomama and Gerakeya, respectively (Table 3). The observed prevalence of anemia in this study was lower than that of EDHS [1] national survey report (54\%) for preschool children. Severe anemia (Hgb < 7) in children was found in Gerakeya (8.5\%). The median level of urinary iodine excretion found in this survey was $1.75 \mu \mathrm{g} / \mathrm{L}$ (Table 4). Urinary iodine excretion below $2 \mu \mathrm{g} / \mathrm{dl}$ in children was found in $73.3 \%$ and $60.5 \%$ of Lalomama and Gerakeya, respectively. Prevalence of goiter rate in Gerakeya is nil although urinary iodine excretion shows existence of severe iodine deficiency disorder.

\section{Land area and use}

Eighty one percent of the participating households in this study reported having land size less than one hectare with a mean land holding of 0.6 hectare. Secondary data from the district office shows that the area is highly eroded and most of the land is non-productive and uncultivable. In addition to the small size, most of the plots are fragmented at different places around hill sides which make them difficult to utilize. There is no irrigation scheme in the area.

\section{Child feeding practices}

More than half of the mothers in both districts reported starting breastfeeding immediately within the first hour of delivery (Table 5). The proportion of mothers who breastfed their babies immediately were significantly higher in Lalomama (73.1\%) compared to Gerakeya (52.9\%). Only about half of the mothers reported to give colostrum to their children and instead gave pre-lacteal feeding of butter/water to the newborn in the first three days after delivery as a cultural practice. Exclusive breastfeeding up to 6 months was practiced by less than $20 \%$ of the households.

\section{Growth-monitoring and morbidity}

As reported by the mothers, the percentage of children who had vaccination card and had been weighed three months before the survey was $71.7 \%$ and $77.5 \%$, respectively (Table 6). The prevalence of sickness among the children two weeks prior to the survey was $28.9 \%$. Cough was the most (59.2\%) and diarrhea was the second (26.5\%) prevalent illness reported.

\section{Water and sanitation}

Half (50.8\%) of the households got water from unprotected wells or springs (Table 7). Open bush/field was used as toilets by $96 \%$ and $73 \%$ of respondents in Lalomama and Gerakeya respectively. The proportion of households reported having soap in the house on the survey date were $54.2 \%$. 


\section{Focus Group Discussion (FGD)}

According to focus group discussants, a range of socio-economic, demographic, environmental and cultural barriers were forwarded to influence the nutritional status of children and household food security. Major problems related to food insecurity and nutrition included lack of enough arable land, unreliable rain fall (time and amount), environmental degradation and extension of desertification, fog, pests, lack of modern agricultural skill, shortage of improved crops and animal variety (productive, drought and disease resistant) and absence of irrigation schemes.

\section{Associations of selected variables with child nutritional status}

Bi-variate analyses were performed on various selected variables (Table 8) with the nutritional indices of all children to determine the possible associations of each variable with rate of malnutrition in the study area. The prevalence of stunting, underweight and wasting is lower in households which have oxen/cow and goat/sheep. Similarly, children born to households having small farmland size, less than a hectare, were more stunted, underweight and wasted than children born to households having farmland over a hectare. Large family size and absence of additional income were also correlated with percent stunted and underweight.

\section{DISCUSSION}

The malnutrition level observed from anthropometric measurement of children is in agreement with similar studies [9]. In the study, it was found that female children were more wasted and less stunted than male children. The result is similar to the investigation of EDHS [1]. The prevalence rate of Bitot's spot in children exceeded the WHO criterion of $0.5 \%$, for declaring vitamin A deficiency (VAD) and Xerophthalmia as a public health problem in the preschool aged group. The prevalence of corneal scar also exceeded the WHO criterion of $0.05 \%$ [10]. The overall prevalence of Bitot's spot (3.5\%) is similar with a FAO/ BSF report of 3.4\% [11] but higher than the national prevalence rate of $1.7 \%$ [12]. The high prevalence of VAD in this survey was indicative of how the study households are vulnerable to overall food insecurity. The high prevalence of anemia observed in the study might be attributed due low dietary intake of iron rich foods or it could be caused by parasite infestation. The latter was, however, not confirmed by laboratory analysis.

Both Urinary Iodine Excretion and observed goiter rate show existence of severe (>60\%) iodine deficiency in Lalomama district. According to Urinary Iodine Excretion the situation in Gerakeya was also worse. Iodine deficiency is one of the leading micronutrients affecting the entire population of the nation (17). According to WHO/ICCIDD/UNICEF [8], a total goiter rate of 5\%, in primary school children (612 years) is indicative of a public health risk of adverse functional consequences and when higher than $30 \%$, the problem is severe and should be of priority and needs to be addressed. National prevalence rate of goiter was more than $39 \%$ in children aged 6-12 years $[12,13]$. The median Urinary Iodine Excretion found in this survey was $1.75 \mu \mathrm{g} / \mathrm{L}$ (Table 4). The low urinary iodine level in Lalomama was consistent with a high rate of goiter (7.4\%) observed compared to Gerakeya district.

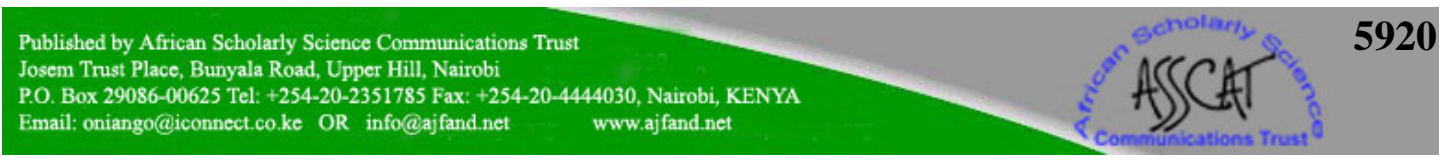




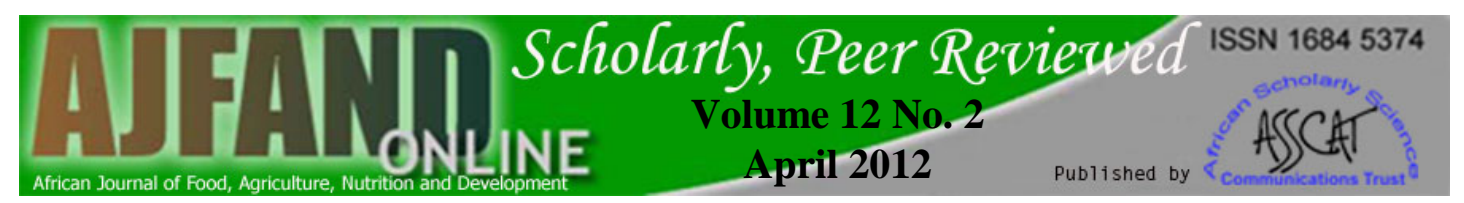

Access to use of agricultural land is one of the necessary conditions of food security for a rural community [14]. Most of the households do not produce enough food from their own farm and food shortage is expected every year in both districts. According to focus group discussants small land size, absence of irrigation and non-conducive environmental conditions are among the reasons for low productivity. Breastfeeding is found to be a common practice in the studied community. Giving of pre-lacteal foods instead of colostrum might be the cause for lowered nutritional status of the children as they expose the newborn to infection [7, 15]. Growth monitoring use observed in this survey is fairly high compared to FAO/BSF report [11]. The poor hygiene and sanitation in this study has also been reported by other researchers [16]

\section{CONCLUSION}

In conclusion, the high level of malnutrition in the study districts provides a good basis for understanding that the communities are most vulnerable to malnutrition, food insecurity, and poor child care. Therefore, a strong promotion of various income generating activities such as off-farming: fattening and in-house feeding of animals, water harvesting, participating youth on other complementary agricultural practices (examples Beehives, fattening, forestry), provision of loans to promote small-scale business and market based production might help to increase additional income and overcome the food insecurity. In addition, promotion of family planning is vitally important and needed. Resettlement may also be taken as an option incase the agricultural and other interventions do not work in the area. To solve the problem in the long-term, conservation, rehabilitation, reforestation and introduction of drought resistant crops might help.

\section{ACKNOWLEDGMENT:}

We would like to thank Ethiopian Health and Nutrition Research Institute, Food and Agriculture Organization of the United Nations and Belgium Survival Fund for logistic and financial support of the study. 


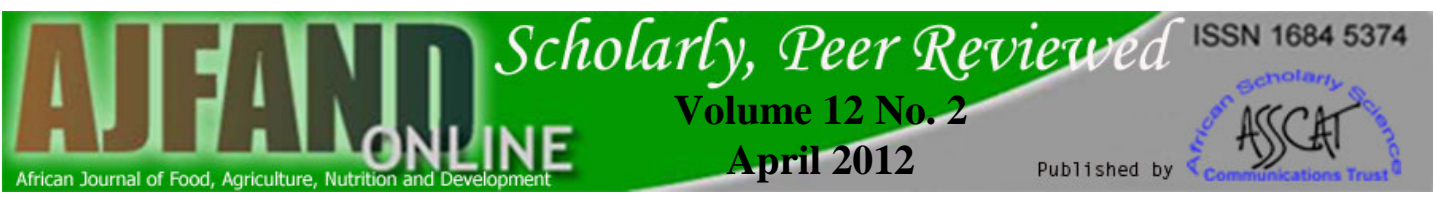

Table 1: Demographic characteristics of the households/head

\begin{tabular}{|c|c|c|}
\hline Variables & Gerakeya & Lalomama \\
\hline & $(\mathrm{N}=99)$ & $(\mathrm{N}=100)$ \\
\hline Female headed HHs & $67.7 \%$ & $52.0 \%$ \\
\hline Read\& write, HH head & $49.5 \%$ & $50.8 \%$ \\
\hline \multicolumn{3}{|l|}{ HH head Occupation } \\
\hline Agriculture & $69.7 \%$ & $96.0 \%$ \\
\hline Small trade/business & $21.2 \%$ & $1.0 \%$ \\
\hline Others & $9.1 \%$ & $3.0 \%$ \\
\hline \multicolumn{3}{|l|}{ HH_head Age } \\
\hline$<20$ years & $10.1 \%$ & $2.0 \%$ \\
\hline 20-30 years & $45.5 \%$ & $49.5 \%$ \\
\hline $30-45$ years & $34.3 \%$ & $33.3 \%$ \\
\hline$>45$ years & $10.1 \%$ & $15.2 \%$ \\
\hline \multicolumn{3}{|l|}{ Family size } \\
\hline$\leq 3$ & $52.5 \%$ & $43.2 \%$ \\
\hline 4 to 6 & $38.4 \%$ & $49.2 \%$ \\
\hline$\geq 7$ & $9.1 \%$ & $7.5 \%$ \\
\hline
\end{tabular}




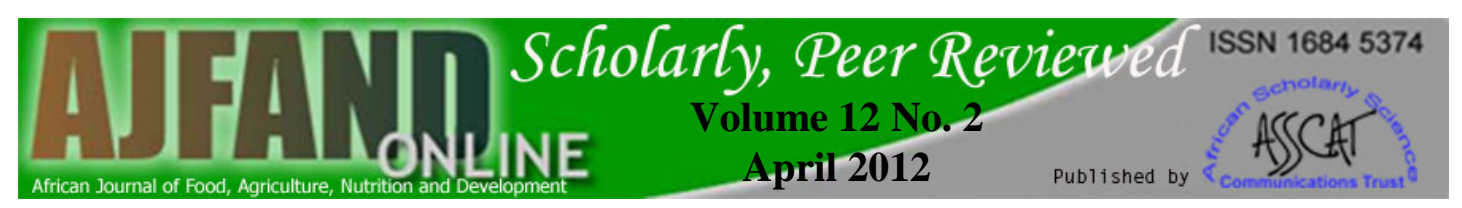

Table 2: Prevalence of Xerophthalmia in children $(\mathrm{N}=115)$ as diagnosed clinically

\begin{tabular}{|c|c|c|c|c|c|c|}
\hline Districts & $\mathbf{N}$ & $\begin{array}{l}\text { \% Bitot`s } \\
\text { spots }\end{array}$ & $\begin{array}{l}\text { \% Night } \\
\text { Blindness }\end{array}$ & $\begin{array}{l}\text { \% Corneal } \\
\text { Xerosis }\end{array}$ & $\begin{array}{l}\text { \% Corneal } \\
\text { scar }\end{array}$ & $\begin{array}{l}\% \\
\text { Ulceration }\end{array}$ \\
\hline Lalomama & 58 & 3.5 & 3.1 & 0.0 & 3.8 & 0.0 \\
\hline Gerakeya & 57 & 3.6 & 0.0 & 1.8 & 1.7 & 1.8 \\
\hline
\end{tabular}

Table 3: Level of hemoglobin in children $(\mathrm{N}=94)$

\begin{tabular}{|l|l|l|l|l|l|}
\hline District & $\mathbf{N}$ & \% Hgb $<$ 7 & \% Hgb 7-11 & \% Hgb < 11 & \% Hgb $\geq \mathbf{1 1}$ \\
\hline Lalomama & 35 & 0 & 8.6 & 8.6 & 91.4 \\
\hline Gerakeya & 59 & 8.5 & 16.9 & 25.4 & 74.6 \\
\hline
\end{tabular}

Table 4: Urinary iodine level and goiter rate in children 6-12 years $(\mathrm{N}=88)$

\begin{tabular}{|l|l|l|l|l|l|l|}
\hline District & $\mathbf{N}$ & Severe & Moderate & Mild & Normal & goiter \\
& & $<\mathbf{2 \mu g} / \mathbf{d l}$ & $\mathbf{2 - 5} \mu \mathbf{g} / \mathbf{d l}$ & $\mathbf{6 - 1 0} \boldsymbol{\mu g} / \mathbf{d l}$ & $>\mathbf{1 0} \boldsymbol{\mu g} / \mathbf{d l}$ & rate \\
\hline Lalomama & 45 & $73.3 \%$ & $20.0 \%$ & $6.7 \%$ & $0 \%$ & 7.4 \\
\hline Gerakeya & 43 & $60.5 \%$ & $30.2 \%$ & $7.0 \%$ & $2.3 \%$ & 0 \\
\hline
\end{tabular}




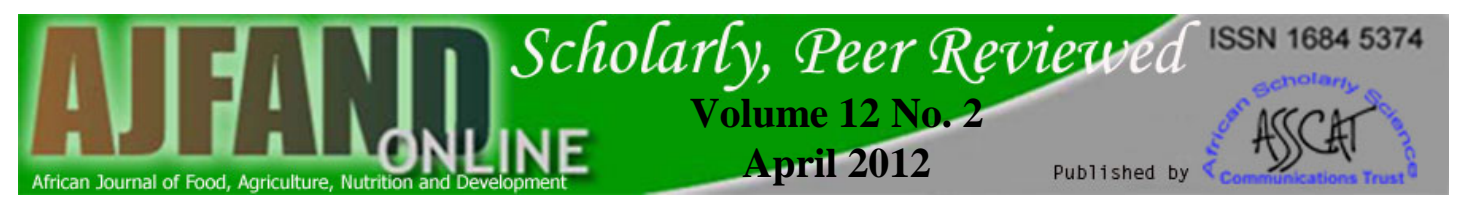

Table 5: Child feeding practices $(\mathrm{N}=130)$

\begin{tabular}{|l|l|l|}
\hline Variables & $\begin{array}{l}\text { Lalomama } \\
(\mathbf{n}=\mathbf{6 6})\end{array}$ & $\begin{array}{l}\text { Gerakeya } \\
(\mathbf{n}=\mathbf{6 4})\end{array}$ \\
\hline \% Children breastfed & 100 & 100 \\
\hline \% Children exclusively breastfed for 6 month & 19.0 & 15.8 \\
\hline \% Children breastfed within an hour after delivery & 73.1 & 52.9 \\
\hline \% Children given colostrum & 53 & 49.2 \\
\hline \% Children given pre-lacteal food & 70.7 & 59.6 \\
\hline
\end{tabular}

Table 6: Growth monitoring and morbidity among preschool children $(\mathbf{N}=151)$

\begin{tabular}{|l|l|l|l|}
\hline \multicolumn{2}{|c|}{ Variables } & Lalomama & Gerakeya \\
\hline \% Child weighed in the last three months & $\mathbf{N}=\mathbf{7 6}$ & $\mathbf{N}=\mathbf{7 5}$ \\
\hline \% Child has vaccination card & 68 & 89.7 \\
\hline \% Child sick 2-weeks before data collection & 33.9 & 24.2 \\
\hline \multirow{4}{*}{ \% Type of disease } & Diarrhea & 73.8 & 69.4 \\
\cline { 2 - 4 } & Cough & 22.2 & 38.5 \\
\cline { 2 - 4 } & Fever & 69.4 & 30.8 \\
\cline { 2 - 4 } & Eye infection & 0 & 23.1 \\
\cline { 2 - 4 } & Intestinal parasites & 2.8 & 7.7 \\
\hline
\end{tabular}




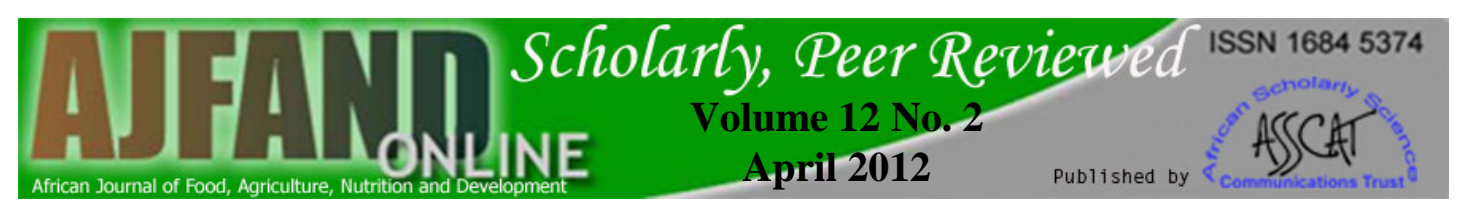

Table 7: Water and sanitation among the households $(\mathrm{N}=199)$

\begin{tabular}{|l|l|c|c|}
\hline \multicolumn{2}{|c|}{ Variables } & Lalo mama & Gera keya \\
\hline \multirow{2}{|l|}{ \% Water source } & Protected well/spring & $\mathbf{N 9}$ & $\mathbf{N}=\mathbf{1 0 0}$ \\
\cline { 2 - 4 } & Unprotected well/spring/river & 40.4 & 66.0 \\
\cline { 2 - 4 } & Pipe water & 16.2 & 4.0 \\
\hline \multirow{2}{*}{ \%Type of toilets } & Traditional pit latrine & 4.0 & 27.0 \\
\cline { 2 - 4 } & Bush/open field & 96.0 & 73.0 \\
& & 64.4 & 51.0 \\
\hline \%HH have soap in the house on survey day & & \\
\cline { 2 - 4 }
\end{tabular}

Table 8: Correlation of Nutritional status of children with selected variables $(\mathbf{n}=$ 130)

\begin{tabular}{|l|l|r|r|r|r|r|r|}
\hline \multirow{2}{*}{ Variables } & \multirow{2}{*}{ Levels } & \multicolumn{2}{|c|}{ Stunted } & \multicolumn{2}{|c|}{ Under weight } & \multicolumn{2}{|c|}{ Wasted } \\
\cline { 3 - 8 } & & $\mathrm{N}$ & \multicolumn{1}{l|}{$\%$} & $\mathrm{~N}$ & $\%$ & $\mathrm{~N}$ & \multicolumn{1}{c|}{$\%$} \\
\hline No. of oxen HH owned & $\bullet$ None & 79 & 55.2 & 61 & 40.4 & 12 & 9.8 \\
& $\bullet \geq 1$ & 30 & 50.8 & 25 & 39.1 & 5 & 5.3 \\
\hline No. of sheep/ goat HH & $\bullet$ None & 79 & $* 58.1$ & 61 & 42.4 & 13 & 9.8 \\
owned & $\bullet \geq 1$ & 30 & 45.5 & 25 & 35.2 & 4 & 5.3 \\
\hline Size of land for agriculture, & $\bullet$ None & 23 & 61.8 & 21 & 40.2 & 4 & 16.4 \\
owned /in hectare/ & $\bullet 0.0-0.9$ & 49 & 59.8 & 51 & 40 & 8 & 11.3 \\
& $\bullet 1-4$ & 15 & 47.2 & 12 & 39.6 & 5 & 8.8 \\
\hline Additional income per & $\bullet 0$ & 20 & 57.1 & 18 & 48.6 & 2 & 5.6 \\
month in Birr & $\bullet 1-60$ & 46 & 53.5 & 36 & 39.1 & 6 & 6.7 \\
& $\bullet \geq 61$ & 41 & 52.6 & 31 & 37.8 & 9 & 11.3 \\
\hline Family size & $\bullet \geq 5$ & 80 & 58.7 & 54 & 47.6 & 7 & 11.1 \\
& $\bullet<5$ & 35 & 56.0 & 30 & 36.0 & 17 & 11.3 \\
\hline
\end{tabular}

*Statistically significant at 5\% level of significance 


\section{REFERENCES}

1. EDHS. Ethiopian Demographic Health Survey. Central Statistics authority of Ethiopia and Macro International Inc. 2005: 12 - 45.

2. Rosalind SG, Yewelsew A, Hambidge KM, Isabel A, Aklilu T and JS Barbara Inadequate feeding practices and impaired growth among children from subsistence farming households in Sidama, Southern Ethiopia. Maternal and Child Nutrition 2009; 5: 260 - 275

3. UNHDI. United Nations Human Development Index; 2009.

4. Rayhan I and SH Khan Factors causing malnutrition among under five children in Bangladesh, Asian Network for Scientific Information. Pakistan Journal of Nutrition. 2006; 5 (6): 558-562.

5. Girma W and T Genebo Determinants of Nutritional Status of Women and Children in Ethiopia. ORC Macro, Calverton, Maryland, USA. 2002: 38-143.

6. Christiaensen $\mathbf{L}$ and $\mathbf{H}$ Alderman Child Malnutrition in Ethiopia: Can Maternal Knowledge Augment The Role of Income? Africa Region Working Paper Series. 2001: 22: 1-22.

7. WHO. World Health Organization. Infant and young child feeding: model chapter for textbooks for medical students and allied health professionals, 2009, WHO, Geneva, 39-41.

8. WHO/ICCIDD/UNICEF. World Health Organization/International Council for the Control of the Iodine Deficiency Disorders / United Nations Children's Fund. Assessment of iodine deficiency disorders and monitoring their elimination: A guide for program managers, $3^{\text {rd }}$ ed., Geneva, World Health Organization 2007: 28-37.

9. Alemu M, Bekele T, Tassew W, Nicola J, John S, Tekie A and A Getachew Child nutritional status in poor Ethiopian households: The role of gender, assets and location. Working paper 26, Young Lives, Save the Children UK, 2005: 2-17.

10. Alfred S Vitamin a deficiency and its consequences: A field guide to detection and control. $3^{\text {rd }}$ edition. Who. Geneva. 1995:34.

11. FAO/BSF. Food and Agriculture Organization of the United Nations/ Belgium Survival Fund. Nutrition and Household Food Security in Northern Shewa and Southern Tigray, Report, Addis Ababa, Ethiopia. 2004: 16 - 17.

12. EHNRI. Ethiopian Health and Nutrition Research Institute. National micronutrient survey technical report, 2006. 


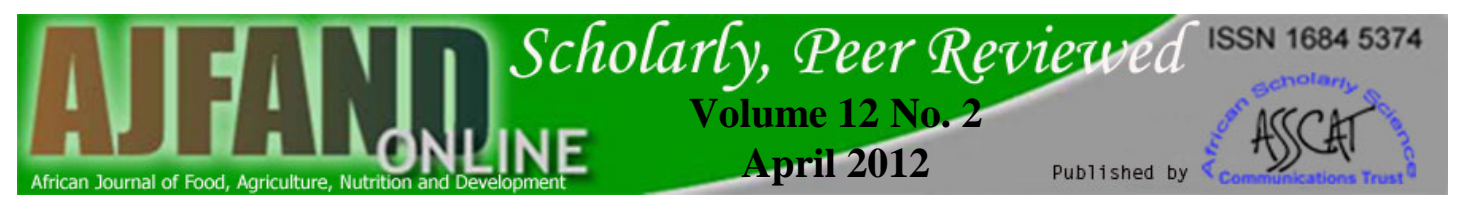

13. Dawit S, Seifu H, Carl KL, Martin EK and K Patrick Post-production Losses in Iodine Concentration of Salt Hamper the Control of Iodine Deficiency Disorders: A Case Study in Northern Ethiopia, J HEALTH POPUL NUTR 2010; 28(3): 238-244.

14. Melkie E Assessment of nutritional status of preschool children of Gumbrit, North West Ethiopia. Ethiop.J.Health Dev 2007; 21(2): 125-129.

15. Elizabeth JB, Linda CS and F Nadra Early Initiation of and Exclusive Breastfeeding in Large-scale Community-based Programs in Bolivia and Madagascar J HEALTH POPUL NUTR 2006; 24(4): 530-539.

16. Andrew H, Tamiru K, Tsegaye D, Tedbabe D and L Seung National survey of the health and nutrition of schoolchildren in Ethiopia Tropical Medicine and International Health.2008; 13 (12):1518-1526.

17. Cherinet $\mathbf{A}$ and $\mathbf{Y}$ Berhane The goitre rate, its association with reproductive failure, and the knowledge of iodine deficiency disorders (IDD) among women in Ethiopia: Cross-section community based study, BMC Public Health. 2007; 7(316): 1-7. 